\title{
Candida albicans Infections: a novel porcine wound model to evaluate treatment efficacy
}

Joel Gil*, Michael Solis, Alexander Higa and Stephen C. Davis

\begin{abstract}
Candida albicans is a common cause of opportunistic mycoses worldwide and a major contributor in wound infections. The purpose of this study was to establish a fungal wound model and analyze the effects of a common antifungal agent against the proliferation of three C. albicans strains. Second degree burns were created, and then inoculated with one of three different $C$. albicans ATCC strains: 10261 reference strain, 64550 fluconazole resistant and 26310 fluconazole sensitive. After fungal inoculation, every wound was covered with dressings for $4 \mathrm{~h}$ to allow fungal colonization on every wound bed. After $4 \mathrm{~h}$, the dressings were removed, and each wound was treated either once or twice daily with a topical terbinafine hydrochloride or left untreated. On days 2, 4 and 7 post inoculation, three wounds from each treatment group were scrub cultured and quantified. On day 2, wounds infected with the sensitive strains 26310 and 10261 and treated twice showed a significant reduction when compared against those infected wounds receiving once daily treatment. On day 4, wounds which were infected with C. albicans fluconazole sensitive (ATCC 26310) showed a significant reduction in fungal cell counts with treatment applied twice daily. A significant reduction in the colony counts was exhibited in all three strains at the seventh day with active as compared to the non-treated wounds. Twice daily treatment resulted in a lower fungal count than once daily treatment. Neither treatment was able to entirely eradicate C. albicans during the duration of this study. Establishing a reliable fungal wound model will help in the translational goal of identifying new antifungal that could be used clinically by wound care providers.
\end{abstract}

Keywords: Candida albicans, Antifungal, Porcine, Wound, Biofilm model, New model, Yeast, Porcine model, Infection, Burns, Antifungal

\section{Introduction}

Superficial fungal infections, such as dermatophytosis, onychomycosis and superficial Candida infections, are common and can be caused by a wide range of fungi [1]. Fungal infections are a common cause of morbidity, mortality, and cost in critical care populations, including burns [1-5]. Also fungus infection as Candidiasis has been found in chronic and surgical wounds [6, 7].

C. albicans is a normal component of the gastrointestinal tract, the oral cavity, and the vagina. It's also an opportunistic pathogen, commonly causing infections

\footnotetext{
*Correspondence: jgil@med.miami.edu
}

Present Address: Miller School of Medicine, Dr. Phillip Frost Department of Dermatology and Cutaneous Surgery Wound Healing Research

Laboratory Miami, University of Miami, Miami 33136, FL, United States such as denture stomatitis, thrush, burn infections and urinary tract infections. C. albicans can also cause more serious systemic infections, these infections are often transmitted in hospitals [8].

Thermal injury is a serious type of trauma requiring care in specialized units. It is estimated that about 2.5 million individuals in the United States sustain burns requiring medical attention each year [9]. More than 100,000 of these patients are hospitalized, and there are approximately 12,000 deaths per year due to thermal injury [10]. Burn patients are cited as being among the highest risk groups for invasive fungal infections [11-16]. The burn patients loss the barrier function of the skin $[17,18]$, the use of topical and systemic antibiotics to control bacterial infections $[8,19,20]$, and 
the alteration of the immune system [21-23] leaves the thermally injured patient at an increased risk of infection by opportunistic organisms, including Candida. Several species of Candida have become common secondary pathogens that have become responsible for a growing number of deaths in burn patients $[5,6,8,17$, 24-26].

The list of antifungals used to treat infections with Candida is extensive. Some of these treatments include topical treatments such as chlorohexidine, clotrimazole, miconazole and ketoconazole; and oral therapies like amphotericin B, nystatin and itraconazole [27, 28]. The efficacy of each treatment depends of the specific virulence of each Candida species and the area of the infection [29]. Terbinafine has been demonstrated to have antifungal activity in vitro [30-32]. Widely varying minimum inhibitory concentration (MIC) have been reported for Candida species, and terbinafine has generally been considered to have limited activity against Candida albicans yeasts in vitro [33]. In several in vitro studies terbinafine activity against $C$. albicans has been primarily fungistatic $[34,35]$. The mechanism of action of terbinafine involves the specific inhibition of fungal squalene epoxidase, resulting in ergosterol deficiency and accumulation of intracellular squalene that interfere with normal fungal membrane function in C. albicans [36-38].

While other animal models have been used to test the efficacy of antifungals, the majority of these use rats, mice and guinea pigs [39-44]. Since swine have skin that is anatomically and physiologically similar to humans and a strong correlation in wound healing studies have been seen, we used them as our experimental animal [45-50]. The purpose of this study was to describe a porcine burn model for the study of C. albicans wound infections and determine if over-the-counter (OTC) treatments are effective against different antibiotic resistant strains. This porcine burn model has been used previously to evaluate several agents in vivo on bacterial infections [51-53]. In this model we studied three (3) different $C$. albicans strains including a commonly used strain, a fluconazole resistant and a fluconazole sensitive strains $[54,55]$. The selected strains of American Type Culture Collection (ATCC) were selected to effectively compare the treatment groups in this model. C. albicans ATCC 10261 is a commonly used reference strain to challenge antifungal agents [56-58]. C. albicans ATCC 64550 has been used as a fluconazole-resistant Candida strain in previous studies $[59,60]$. C. albicans ATCC 26310 utilized as a fluconazole-sensitive strain in several studies [61-63]. This study also compared once versus twice topical terbinafine hydrochloride treatment regimens to determine if the frequency of treatment application made any differences in antifungal activity.

\section{Methods and materials}

\section{Experimental animals}

Two young female specific pathogen free (SPF) pigs (Sus scrofa domesticus) were purchased from Looper Farm (Granite Falls, NC) weighing 25-30 kg were kept in house for two weeks prior to initiating the experiment. These animals were fed a basal diet ad libitum and housed individually in our animal facilities (meeting USDA compliance) with controlled temperature (19-21 $\left.{ }^{\circ} \mathrm{C}\right)$ and lights (12 h/12 h LD).

\section{Anesthetics, analgesics and euthanasia}

The animals were anesthetized with a cocktail dose (intramuscular injection) prepared with their corresponding weights. The cocktail used for sedation was made with Telazol $\mathrm{HCl}(100 \mathrm{mg} / \mathrm{mL})$, given at a dose of $1.4 \mathrm{mg}$ per kilogram; Xylazine $(100 \mathrm{mg} / \mathrm{mL})$, given at a dose of $2.0 \mathrm{mg}$ per kilogram; and Atropine $(0.54 \mathrm{mg} /$ $\mathrm{mL}$ ) given at a dose of $0.05 \mathrm{mg}$ per kilogram. Once sedated, animals had endotracheal tube inhalation of an isoflurane and oxygen combination during each procedure. For analgesics, each animal received a fentanyl transdermal patch (50 $\mu \mathrm{g}$ per hour) and Buprenorphine $(0.3 \mathrm{mg} / \mathrm{mL})$, given at a dose of $0.03 \mathrm{mg}$ per kilogram. Upon the completion of the wound recoveries, the animals were first anesthetized and after the procedure was finished each animal by euthanized by receiving via an intramuscular injection Euthasol (pentobarbital sodium $390 \mathrm{mg} / \mathrm{mL}$ ), given at a dose of $1 \mathrm{~mL}$ per $10 \mathrm{lbs}$.

\section{Wounding}

Prior to surgery the animals were anesthetized, the hair on the back of the pigs was clipped with standard animal clippers. Skin on both sides of the animals was prepared by washing with a non-antibiotic soap (Neutrogena ${ }^{\circledR}$ ) and sterile water. The animals were blotted dry with sterile gauze. Eighty one (81) second-degree burn wounds were made in the paravertebral and thoracic area on each animal by using specially designed cylindrical brass rods weighing $358 \mathrm{~g}$ that was heated in a boiling water bath to $100{ }^{\circ} \mathrm{C}$ [64]. A rod was removed from the water bath and wiped dry before it is applied to the skin surface to prevent water droplets from creating a steam burn on the skin. The brass rod was held at a vertical position on the skin (six seconds), with all pressure supplied by gravity, to make a burn wound $8.5 \mathrm{~mm}$ diameter $\times 0.8 \mathrm{~mm}$ deep. Immediately after burning, the roof of the burn blister was removed with a sterile spatula. Eighty-one burns were created on each animal for a total of one hundred sixty-two wounds. 


\section{Experimental Design}

On each animal, twenty-seven (27) burn wounds were assigned to one of three C. albicans strains. (Fig. 1: strains below). Nine burns were allocated for three treatment regimens (described below). The burn wounds were made approximately $3-5 \mathrm{~cm}$ from each other. Groups of burns were inoculated, treated, and recovered as described below.

\section{Inoculation}

Fresh cultures of pathogenic isolates were obtained directly from American Type Culture Collection (ATCC, Rockville, Maryland). The inoculums were Candida albicans ATCC 10261 (reference strain), Candida albicans ATCC 64550 fluconazole-resistant and Candida albicans ATCC 26310 fluconazole-sensitive. The frozen fungus was recovered from glycerol stock ( $15 \%$ glycerol, $-80^{\circ} \mathrm{C}$ ). All inoculums' suspensions were made by scraping the overnight growth from a culture plate into $5 \mathrm{ml}$ of normal saline. This resulted in a suspension concentration of approximately 10 [8] colony forming units $/ \mathrm{ml}$ $(\mathrm{CFU} / \mathrm{ml})$. A small amount of the inoculum suspension was plated onto culture media BBL $^{\text {TM }}$ CHROMagar ${ }^{\text {TM }}$ Candida Medium (Becton Dickinson GmbH, Heidelberg/Germany) to quantify the exact amount of viable organisms. The inoculum suspension was used directly to inoculate each site. A $0.025 \mathrm{ml}(25 \mu \mathrm{l})$ aliquot of the suspension was deposited into the center of each burn. The suspension was lightly scrubbed into the test site for ten seconds using a sterile Teflon spatula and left for 3 min prior to covering with a polyurethane film dressing
(Tegaderm Transparent Dressing; 3 M Health Care, St. Paul, MN USA) for $4 \mathrm{~h}$ to allow the organism colonized the burn area. The film dressings were secured in place with tape and the animals were wrapped with self-adherent bandages.

Four hours post-fungal inoculation, wounds were uncovered and treated with antifungal agent (topical terbinafine hydrochloride). Wounds remained either untreated or received either once or twice daily treatment for six days. Inoculated wounds were randomized around the animal within their designated group. Approximately $250 \mu \mathrm{l}$ of the treatment was applied over each wound and then gently spread over the wound and adjacent normal skin with a sterile applicator. Treatments including untreated control were covered with same dressing as previously described to prevent any cross contamination of treatments.

\section{Microbiological recovery}

Nine burns were cultured from each group at Days 2, 4 and 7 post inoculation from each C. albicans strain. Each burn was cultured only once. The area was encompassed by a sterile stainless-steel cylinder $(22 \mathrm{~mm}$ outside diameter) held in place by two handles. One $\mathrm{ml}$ of scrub solution was pipetted into the stainless-steel cylinder and the site was scrubbed with a sterile Teflon spatula for $30 \mathrm{~s}$ using a modified scrub technique [65]. Serial dilutions of all recoveries were made and recovered bacteria was quantified using the Spiral Plater System, which deposits a small-defined amount $(50 \mu \mathrm{l})$ of suspension over the surface of a rotating agar

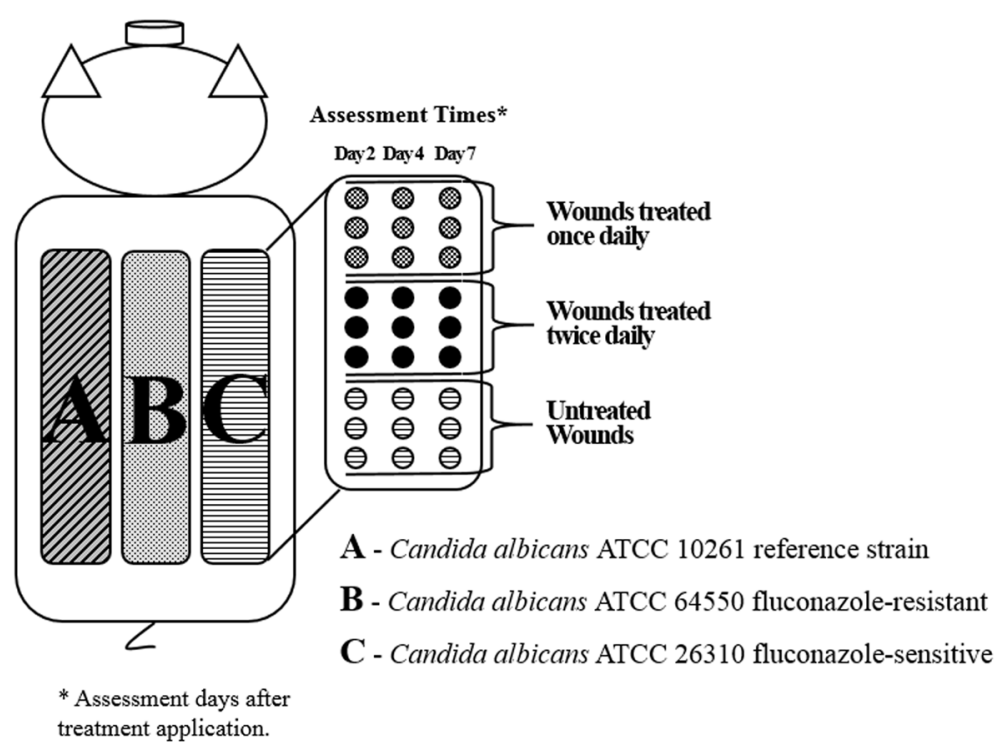

Fig. 1 Experimental Design 
plate. Candida albicans was grown on selective $\mathrm{BBL}^{\mathrm{TM}}$ CHROMagar $^{\mathrm{TM}}$ Candida Medium (Becton Dickinson $\mathrm{GmbH}$, Heidelberg/Germany) overnight at $37^{\circ} \mathrm{C}$. Colonies on the plates were counted and the colony forming units per $\mathrm{mL}(\mathrm{CFU} / \mathrm{ml})$ calculated.

\section{Results}

A total of one hundred ninety-eight (198) wounds were evaluated. Treatment application for once or twice daily resulted in significant $(p<0.05)$ reductions for all $C$. albicans strains in comparison to the untreated control group as shown in Figs. 2, 3 and 4. The data also shows those wounds treated twice exhibiting

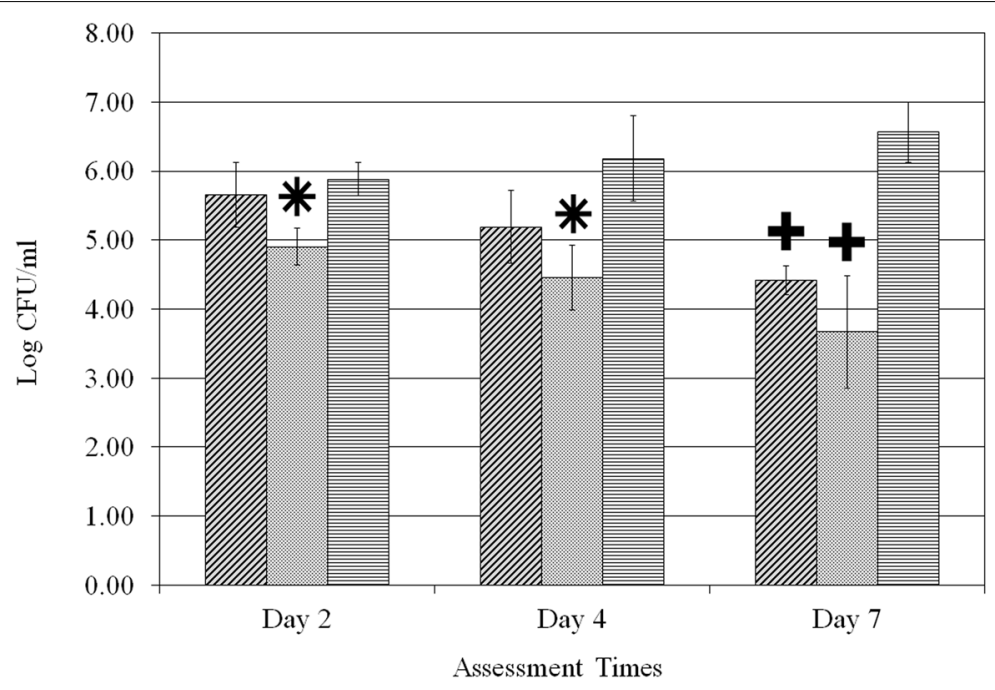

Treated once daily $\square$ Treated twice daily 冒 Untreated

Fig. 2 C. albicans (ATCC 10261) reference strain count. Comparison between different treatment regimens per assessment days. ${ }^{*} p<0.05$ compared to other two treatment regimens, $+p<0.05$ compared to Untreated

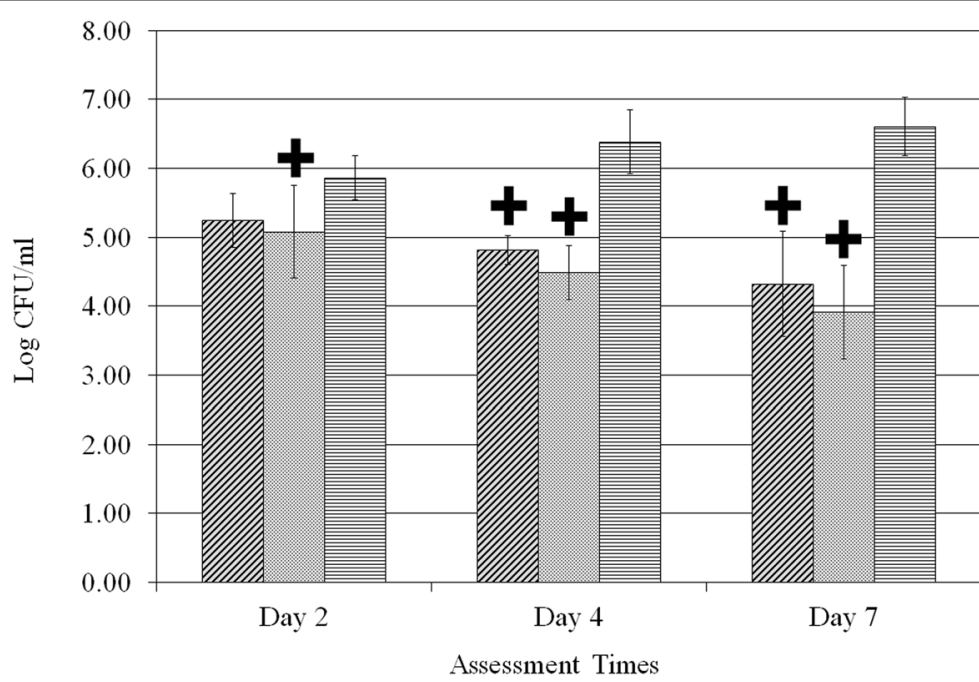

Treated once daily $\square$ Treated twice daily 目 Untreated

Fig. 3 C. albicans (ATCC 64550) fluconazole-resistant count. Comparison between different treatment regimens per assessment days. $+p<0.05$ compared to untreated 


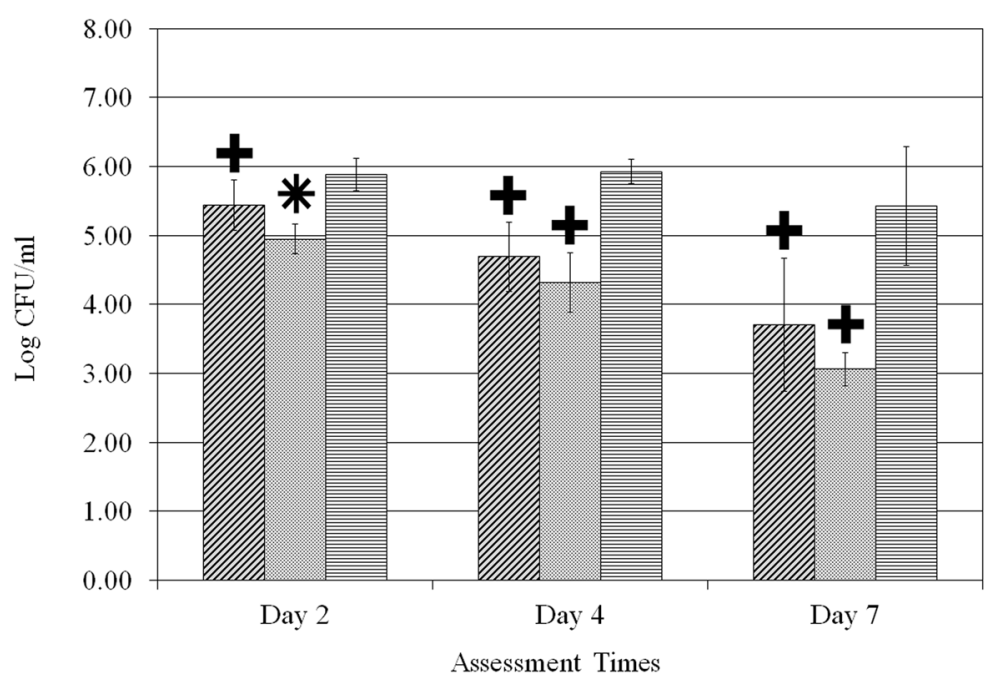

Treated once daily $\square$ Treated twice daily 国 Untreated

Fig. 4 C. albicans (ATCC 26310) fluconazole-sensitive count. Comparison between different treatment regimens per assessment days. ${ }^{*} p<0.05$ compared to other two treatment regimens, $\quad+p<0.05$ compared to untreated

lower fungal activity than those wounds treated once. The application of treatment twice daily resulted in a greater than $2.0 \mathrm{Log} \mathrm{CFU} / \mathrm{ml}(p<0.05)$ reduction of all strains of $C$. albicans compared to the untreated control on day 7 (Figs. 2, 3 and 4). For the reference strain C. albicans 10261 the twice daily treatment showed significantly $(p<0.05)$ better efficacy as compared to both once daily and untreated control on days 2 and 4 (Fig. 2). On day 7, treated twice daily wounds continued having significantly $(p<0.05)$ lower fungal counts when compared to those wounds left untreated, while remaining lower than those wounds treated once daily. Wounds infected with C. albicans 64550 (fluconazole resistant strain), on day 2 treated twice daily were significantly $(p<0.05)$ lower than those wounds left untreated a shown in Fig. 3. Both treatment regimens showed significantly $(p<0.05)$ lower fungal activity than untreated control (days 4 and 7 ). The counts for C. albicans 26310 (fluconazole sensitive) were significantly $(p<0.05)$ lower than untreated by both treatment regimens during all three assessment days (Fig. 4). On day 2, those wounds treated twice daily showed significantly $(p<0.05)$ lower counts than both treated once wounds and Untreated control. Those wounds treated twice daily on day 7 were substantially lower than those wounds left untreated, exhibiting the lowest fungal count for any of the three strains.

\section{Discussion}

As shown in this study, the in vivo porcine model offers a useful model that can provide reliable translational data on wound infections on the epidermis and dermis layers. Swine skin structure is very similar to human skin, including having similar epithelial thickness of the stratum corneum [66]. Additionally, the swine model can provide a reliable model because of dermatophytes requiring keratin structures [67] found in said stratum corneum and pigs having a hair density comparable to human [68]. Candida species can be found as a normal flora in humans, commonly in infections related to hair and nails which can cause a systemic infection in the human body [69-71]. Candida albicans has been shown to be both sensitive and resistant to fluconazole [37, 38]. Polymicrobial communities is well known that could colonize chronic wounds, this colonization can delay the healing process $[72,73]$. Recent studies showed that Candida albicans species could be found in a $22 \%$ of the isolations in chronic wounds [74]. Fungistatic characteristics of antifungal drugs, low doses of the drug, duration of the treatment as well interaction with other treatments are some of the reasons why limited treatment efficacy has been seen in patients with fungal infections as well for the resistance of different strains to the drugs [75]. Therapies such as azole fluconazole have been effective against most Candida species and are widely used as 
the first treatment option showed in an in vitro study to decrease the level of a Candidiasis [76]. In this in vitro study, Serpa et al. [73] tested a azole fluconazole treatment against Candida albicans ATCC 64550 fluconazole resistant showing a decrease in the counts after 7 days of treatments, cells were treated twice versus once, previous studies $[50,77]$ demonstrated that this strain have resistance to fluconazole treatments. Using Candida albicans ATCC 10261 as reference strain tested in vitro showed a low MIC when was challenged against fluconazole [78, 79]. In our study, Candida albicans ATCC 26310 fluconazole sensitive showed a decrease in the counts compared to untreated infected wounds however after 7 days the counts were higher to those wounds infected with the fluconazole resistance strain, others studies showed before that this strain decrease the counts after extended period of time more than 7 days [80].

Even when the wounds were treated twice for 6 days it was still insufficient amount to completely eradicate the fungal infection. Other authors demonstrated in vitro the combination of therapies as an effective methodology to reduce the candidiasis [81-83]. Cyclosporine in combination with fluconazole could be an effective treatment to complete eradication of fungal infection since increase the susceptibility to fluconazole due to efflux pump deletion or alteration of stress response caused by calcineurin during azole therapy [84].

Current literature has provided evidence for antifungal compounds to be active against other $C$. albicans strains. Pandolfi et al. [56] has reported evaluations of compounds having the same effects in different strains, with C. albicans ATCC 10261 showing a comparable biofilm activity as the other strains used in an in vitro study. Similarly, other in vitro studies challenging a range of 10-15 C. albicans strains have analyzed of other antifungal compounds not finding any collective difference in the results, such as a comparison including $C$. albicans ATCC 64550 [51].

We have developed a burn infection model which allows the colonization of Candida sp to examine the efficacy of topical and/or systemic antifungal therapies. One of the limitations with this study and all animal models used to assess the activity of antifungals is that they tend to be short-term without underlying comorbidities, and do not necessarily replicate a true clinical infection, with clinical variables such as size, depth and aetiology [85-87].

\section{Conclusions}

This study demonstrates the usefulness of a porcine second-degree burn model in evaluating treatment efficacy against $C$. albicans infections by developing a platform to compare different treatment groups against different strains. These results indicate that wounds treated with a topical terbinafine hydrochloride formulation had substantial reductions against $C$. albicans when comparing to untreated wounds. Despite the fungal presence not being fully eliminated on all wounds, the data in this study shows the significant reduction by treated twice wounds with terbinafine hydrochloride when compared to those wounds left untreated, thereby it can be extrapolated that the fungal bioburden can be eradicated with additional days.

Overall, we found that terbinafine treatments applied either once or twice a day exhibited lower reductions as the days progressed. Both treatment groups with terbinafine hydrochloride showed a desirable rate of reduction, which should further be investigated with additional assessment days or the in tandem application of another antifungal modality. This model will be beneficial to identify novel therapies that may be use clinically.

\section{Abbreviations}

ATCC: American type culture collection; MIC: Minimum inhibitory concentration; OTC: Over the counter; SPF: Specific pathogen free; CFU: Colony forming units.

\section{Acknowledgements}

Not applicable.

\section{Authors' contributions}

$J$ J and SD contributed to conception and design of the study. JG, AH and MS organized the database. JG performed the statistical analysis. JG, AH and MS perform the study with animals. JG and SD wrote sections of the manuscript. All authors contributed to manuscript revision, read, and approved the submitted manuscript.

\section{Funding}

No funding was obtained for this study.

\section{Availability of data and materials}

The datasets generated and/or analyzed during the current study are not publicly available due raw data not being published for any other publication but are available from the corresponding author on reasonable request.

The study was carried out in compliance with the ARRIVE guidelines.

\section{Declarations}

Ethics approval and consent to participate

Animals were purchased from Looper Farm, Inc, written and informed consent to use the animals in the study was received from swine owners at Looper Farm, Inc.

The experimental animal protocols used for this study were approved by the University of Miami Institutional Animal Care and Use Committee (IACUC) and all the procedures follow the federal guidelines for the care and use of laboratory animals (U.S. Department of Health and Human Services, U.S. Department of Agriculture).

Consent for publication

Not applicable.

Competing interests

No competing interest to report by any of the authors. 
Received: 9 June 2021 Accepted: 24 January 2022

Published online: 04 February 2022

\section{References}

1. Huang, David B, Ostrosky-Zeichner Luis, Wu, Jashin J, Pang, Katie R. Tyring, StephenK.Therapy of common superficial fungal infections. Derma Ther. 2004;17:517-22.

2. Rentz AM, Halpern MT, Bowden R. The impact of candidemia on length of hospital stay, outcome, and overall cost of illness. Clin Infect Dis. 1998;27:781-8.

3. Swoboda SM, Merz WG, Lipsetta PA. Candidemia: the impact of antifungal prophylaxis in a surgical intensive care unit. Surg Infect (Larchmt). 2003:4:345-54.

4. Cochran A, Morris SE, Edelman LS, Saffle JR. Systemic Candida infection in burn patients: a case-control study of management patterns and outcomes. Surg Infect (Larchmt). 2002;3:367-74.

5. Duggan S, Leonhardt I, Hünniger K, Kurzai O. Host response to Candida albicans bloodstream infection and sepsis. Virulence. 2015;6(4):316-26. https://doi.org/10.4161/21505594.2014.988096 (Epub 2015 Mar 18. PMID: 25785541; PMCID: PMC4601378).

6. Khan MA, Khan A, Khan SH, Azam M, Khan MMU, Khalilullah H, Younus $H$. Coadministration of liposomal methylglyoxal increases the activity of amphotericin B against Candida albicans in leukopoenic mice. J Drug Target. 2021;29(1):78-87. https://doi.org/10.1080/1061186X.2020.18033 33 (Epub 2020 Aug 6 PMID: 32723117 ).

7. Wasylyshyn A, Linder KA, Castillo CG, Zhou S, Kauffman CA, Miceli MH. Breakthrough Invasive Fungal Infections in Patients with Acute Myeloid Leukemia. Mycopathologia. 2020;185(2):299-306. https://doi.org/10. 1007/s11046-019-00418-8 (Epub 2020 Jan 14 PMID: 31939052).

8. Matthaiou DK, Blot S, Koulenti D. Candida burn wound sepsis: The "holy trinity" of management. Intensive Crit Care Nurs. 2018;46:4-5. https://doi. org/10.1016/j.iccn.2018.02.001 (Epub 2018 Mar 13 PMID: 29548615).

9. Derkenne C, Ronchi L, Prunet B. Management of Burns. N Engl J Med. 2019;381(12):1188. https://doi.org/10.1056/NEJMc1909342 (PMID: 31532984).

10. Mayhall CG. The epidemiology of burn wound infections: then and now. Clin Infect Dis. 2003;37(4):543-50.

11. Suleyman G, Alangaden GJ. Nosocomial Fungal Infections: Epidemiology, Infection Control, and Prevention. Infect Dis Clin North Am. 2021;35(4):1027-53. https://doi.org/10.1016/j.idc.2021.08.002 (PMID: 34752219)

12. Fridkin SK, Jarvis WR. Epidemiology of nosocomial fungal infections. Clin Microbiol Rev. 1996:9:499-511.

13. Gelfand JA. Infections in burn patients: a paradigm for cutaneous infection in the patient at risk. Am J Med. 1984;76:158-65.

14. Ekenna O, Sherertz RJ, Bingham H. Natural history of bloodstream infections in a burn patient population: the importance of candidemia. Am J Infect Control. 1993;21:189-95.

15. Esposito S. Immune system and surgical site infection. J Chemother. 2001;13(Spec 1):12-6.

16. Charles PE, Doise JM, Quenot JP, et al. Candidemia in critically ill patients: difference of outcome between medical and surgical patients. Intensive Care Med. 2003;29:2162-9.

17. Palackic A, Popp D, Tapking C, Houschyar KS, Branski LK. Fungal Infections in Burn Patients. Surg Infect (Larchmt). 2021;22(1):83-7. https://doi.org/ 10.1089/sur.2020.299 (Epub 2020 Oct 9 PMID: 33035112 ).

18. Yecies T, Mohapatra A, Semins MJ. Outcomes of Endourologic Interventions in Patients with Preoperative Funguria. J Endourol. 2019;33(8):66872. https://doi.org/10.1089/end.2018.0852 (Epub 2019 May 7 PMID: 30924689).

19. Moore EC, Padiglione AA, Wasiak J, Paul E, Cleland H. Candida in burns: risk factors and outcomes. J Burn Care Res. 2010;31(2):257-63. https://doi. org/10.1097/BCR.0b013e3181d0f536 (PMID: 20182372).

20. Hani U, Shivakumar HG, Vaghela R, Osmani RA, Shrivastava A. Candidiasis: a fungal infection-current challenges and progress in prevention and treatment. Infect Disord Drug Targets. 2015;15(1):42-52. https://doi.org/ 10.2174/1871526515666150320162036 (PMID: 25809621).
21. Jeschke MG, van Baar ME, Choudhry MA, Chung KK, Gibran NS, Logsetty S. Burn injury Nat Rev Dis Primers. 2020;6(1):11. https://doi.org/10.1038/ s41572-020-0145-5.PMID:32054846:PMCID:PMC7224101.

22. Abi-Said D, Anaissie E, Uzun O, Raad I, Pinzcowski H, Vartivarian S. The epidemiology of hematogenous candidiasis caused by different Candida species. Clin Infect Dis. 1997;24:1122-8.

23. Fraser VJ, Jones M, Dunkel J, Storfer S, Medoff G, Dunagan WC. Candidemia in a tertiary care hospital: epidemiology, risk factors, and predictors of mortality. Clin Infect Dis. 1992:15:414-21.

24. Rosanova MT, Basilico H, Villasboas M, Finquelievich J, Mónaco A, Pérez G, Berberian G, Alvarez V, Andión E, Santos P. Infecciones fúngicas en una unidad de quemados pediátrica [Fungal infections in a pediatric burn care]. Arch Argent Pediatr. 2011;109(5):441-4. https://doi.org/10.1590/ S0325-00752011000500012 (Spanish PMID: 22042076).

25. Schwab F, Gastmeier P, Hoffmann P, Meyer E. Summer, sun and sepsis-The influence of outside temperature on nosocomial bloodstream infections: A cohort study and review of the literature. PLOS ONE. 2020;15(6): e0234656. https://doi.org/10.1371/journal.pone.0234656.PMID:32559761; PMCID:PMC7304998.

26. Pensler JM, Herndon DN, Ptak H, Bonds E, Rutan TC, Desai MH. Fungal sepsis: an increasing problem in major thermal injuries. J Burn Care Rehab. 1986;7:488-91.

27. Scheibler E, Garcia MCR, da Silva RM, Figueiredo MA, Salum FG, Cherubini K. Use of nystatin and chlorhexidine in oral medicine: Properties, indications and pitfalls with focus on geriatric patients. Gerod. 2017;34:291-8.

28. Eschenauer GA, Nguyen MH, Clancy CJ. Is Fluconazole or an Echinocandin the Agent of Choice for Candidemia. Ann Pharmacother. 2015;49:1068-74.

29. Garcia-Cuesta C, Sarrion-Pérez MG, Bagán JV. Current treatment of oral candidiasis: A literature review. J Clin Exp Dent. 2014;6(5):e576-82. https://doi.org/10.4317/jced.51798.

30. Ryder NS, Mieth H. Allylamine antifungal drugs. Curr Top Med Mycol. 1992;4:158-88.

31. Clayton YM. In vitro activity of terbinafine. Clin Experimen Dermatol. 1989;14:101-3.

32. Ryder NS, Favre B. Antifungal activity and mechanism of action of terbinafine. Rev Contemp Pharma. 1997:8:275-87.

33. Petranyi $G$, Meingassner JG, Mieth $\mathrm{H}$. Antifungal activity of the allylamine derivative terbinafine in vitro. Antimic Agt Chemo. 1987;31:1365-8.

34. Schaude $M$, Ackerbauer $\mathrm{H}$, Mieth $\mathrm{H}$. Inhibitory effect of antifungal agents on germ tube formation in Candida albicans. Mykosen. 1987;30:281-7.

35. Petranyi, G., J. G. Meingassner, and H. Mieth. 1983. SF 86-327:a new antimycotic agent and its antifungal activity in vitro, section M6, p. 15-19. In K. H. Spitzy and K. Karrer (ed.), Proceedings of the 13th International Congress of Chemotherapy, Vienna, Austria, 28 August-2 September 1983. Egermann, Vienna.

36. Petranyi G, Ryder NS, Stiitz A. Allylamine derivatives: new class of synthetic antifungal agents inhibiting fungal squalene epoxidase. Sci. 1984:224:1239-41.

37. Ryder NS. The mechanism of action of terbinafine. Cttnuat and Experimental Dermatology. 1989;14:98-10.

38. Ryder NS. Terbinafine: mode of action and properties of the squalene epoxidase inhibition. Br J Dermatol. 1992;126(Suppl 39):2-7.

39. Silva-Dias A, Miranda IM, Branco J, Cobrado L, MonteiroSoares M, PinaVaz C, Rodrigues AG. In vitro antifungal activity and in vivo antibiofilm activity of cerium nitrate against Candida species. J Antimic Chemo. 2015;70(4):1083-93. https://doi.org/10.1093/jac/dku511.

40. Lazzell AL, Chaturvedi AK, Pierce CG, Prasad D, Uppuluri P, Lopez-Ribot JL. Treatment and prevention of Candida albicans biofilms with caspofungin in a novel central venous catheter murine model of candidiasis. J Antimic Chemo. 2009;64(3):567-70. https://doi.org/10.1093/jac/dkp242.

41. Kucharíková S, Tournu H, Holtappels M, Van Dijck P, Lagrou K. In vivo efficacy of anidulafungin against mature Candida albicans biofilms in a novel rat model of catheter associated Candidiasis. Antimic Agt Chemo. 2010;54(10):4474-5. https://doi.org/10.1128/AAC.00697-10.

42. Bink A, Kucharíková S, Neirinck B, Vleugels J, Van Dijck P, Cammue BPA Thevissen K. The nonsteroidal antiinflammatory drug diclofenac potentiates the in vivo activity of caspofungin against Candida albicans biofilms. J Infect Dis. 2012;206(11):1790-7. https://doi.org/10.1093/infdis/jis594.

43. Zhao J, Cheng Y, Song X, Wang C, Su G, Liu Z. A Comparative Treatment Study of Intravitreal Voriconazole and Liposomal Amphotericin B in an 
Aspergillus fumigatus Endophthalmitis Model. Invest Ophthalmol Vis Sci. 2015;56(12):7369-76. https://doi.org/10.1167/iovs.15-17266.

44. Wiederhold NP, Najvar LK, Matsumoto S, Bocanegra RA, Herrera ML, Wickes BL, Kirkpatrick WR, Patterson TF. Efficacy of the investigational echinocandin ASP9726 in a guinea pig model of invasive pulmonary aspergillosis. Antimic Agt Chemo. 2015;59(5):2875-81. https://doi.org/10. 1128/AAC.04857-14.

45. Sullivan TP, Eaglstein WH, Davis SC, Mertz P. The pig as a model for human wound healing. Wound Rep Regen. 2001;9:66-76.

46. Grada A, Mervis J, Falanga. Research Techniques Made Simple: Animal Models of Wound Healing. J Invest Dermatol. 2018;138(10):2095-105.

47. Liu Y, Chen JY, Shang HT, Liu CE, Wang Y, Niu R, Wu J, Wei H. Light microscopic, electron microscopic, and immunohistochemical comparison of Bama minipig (Sus scrofa domestica) and human skin. Comp Med. 2010;60:142-8.

48. Eaglstein WH, Mertz PM. New methods for assessing epidermal wound healing: the effects of triamcinolone acetonide and polyethelene film occlusion. J Invest Dermatol. 1978;71:382-4.

49. Summerfield A, Meurens F, Ricklin ME. The immunology of the porcine skin and its value as a model for human skin. Mol Immunol. 2015;66:14-21.

50. Meyer W, Schwarz R, Neurand K. The skin of domestic mammals as a model for the human skin, with special reference to the domestic pig. Curr Probl Dermatol. 1978;7:39-52. https://doi.org/10.1159/000401274 (PMID: 752456).

51. Goodwine J, Gil J, Doiron A, et al. Pyruvate-depleting conditions induce biofilm dispersion and enhance the efficacy of antibiotics in killing biofilms in vitro and in vivo. Sci Rep. 2019;9:3763.

52. Davis SC, Mertz PM. Treatment of Wounds with an Oak Bark Formulation: Antimicrobial and Wound Healing Assessments. Ostomy Wound Mgt. 2008:54(10):16-25.

53. Seaton M, Hocking A, Gibran NS. Porcine models of cutaneous wound healing. ILAR J. 2015;56(1):127-38.

54. Kanafani ZA, Perfect JR. Antimicrobial resistance: Resistance to antifungal agents: Mechanisms and clinical impact. Clin Infect Dis. 2008:46:120-8.

55. Khurana A, Sardana K, Chowdhary A. Antifungal resistance in dermatophytes: Recent trends and therapeutic implications. Fungal Genet Biol. 2019;132: 103255. https://doi.org/10.1016/j.fgb.2019.103255 (Epub 2019 Jul 19 PMID: 31330295).

56. Pandolfi F, D'Acierno F, Bortolami M, De Vita D, Gallo F, De Meo A, Di Santo R, Costi R, Simonetti G, Scipione L. Searching for new agents active against Candida albicans biofilm: A series of indole derivatives, design synthesis and biological evaluation. Eur J Med Chem. 2019;1(165):93-106.

57. Mohammadi Z, Giardino L, Palazzi F. Evaluation of the antifungal activity of four solutions used as a final rinse in vitro. Aust Endod J. 2013;39(1):31-4.

58. Shreaz S, Bhatia R, Khan N, Muralidhar S, Manzoor N, Khan LA. Influences of cinnamic aldehydes on $\mathrm{H}+$ extrusion activity and ultrastructure of Candida. J Med Microbiol. 2013;62(Pt 2):232-40. https://doi.org/10.1099/ jmm.0.036145-0 (Epub 2011 Oct 27 PMID: 22034160).

59. Paul-Satyaseela M, Hariharan P, Bharani T, Franklyne JS, Selvakumar T, Bharathimohan K, Kumar CV, Kachhadia V, Narayanan S, Rajagopal S, Balasubramanian $\mathrm{G}$. Novel hydroxamates potentiated in vitro activity of fluconazole against Candida albicans. J Nat Sci Biol Med. 2017;8(1):119-24.

60. D'Arrigo M, Bisignano C, Irrera P, Smeriglio A, Zagami R, Trombetta D, Romeo O, Mandalari G. In vitro evaluation of the activity of an essential oil from Pistacia vera L. variety Bronte hull against Candida sp. BMC Complement Altern Med. 2019;19(1):6.

61. Sohnle P, Hahn B, Erdmann M. Effect of Fluconazole on Viability of Candida albicans over Extended Periods of Time. Antimic Agt Chemo. 1996;40(11):2622-5.

62. Mohd D, Koh S, Abdullah R, Azali A. Evidence of Potent Antibacterial Effect of Fermented Papaya Leaf against opportunistic skin Pathogenic Microbes. Food Res. 2020;4(Suppl. 6):112-7.

63. Pappas PG, Kauffman CA, Andes DR, Clancy CJ, Marr KA, Ostrosky-Zeichner L, Reboli AC, Schuster MG, Vazquez JA, Walsh TJ, Zaoutis TE, Sobel JD. Clinical Practice Guideline for the Management of Candidiasis: 2016 Update by the Infectious Diseases Society of America. Clin Infect Dis. 2016;62(4):e1-50

64. Davis SC, Mertz PM, Bilevich ED, Cazzaniga AL, Eaglstein WH. Early debridement of second-degree burn wounds enhances the rate of epithelization-an animal model to evaluate burn wound therapies. J Burn Care Rehabil. 1996;17(6 Pt 1):558-61. https://doi.org/10.1097/00004630199611000-00014.

65. Davis SC, Ricotti C, Cazzaniga A, Welsh E, Eaglstein WH, et al. Microscopic and physiologic evidence for biofilm-associated wound colonization in vivo. Wound Repair Regen. 2008;16:23-9.

66. Summerfield A, Meurens F, Ricklin ME. The immunology of the porcine skin and its value as a model for human skin. Mol Immunol. 2015;66(1):14-21.

67. Pippin MM, Madden ML. Tinea Cruris. In: StatPearls. Treasure Island: StatPearls Publishing; 2021.

68. Khiao In M, Richardson KC, Loewa A, Hedtrich S, Kaessmeyer S, Plendl $J$. Histological and functional comparisons of four anatomical regions of porcine skin with human abdominal skin. Anat Histol Embryol. 2019:48(3):207-17.

69. Rafat Z, Hashemi SJ, Ahamdikia K, Daie Ghazvini R, Bazvandi F. Study of skin and nail Candida species as a normal flora based on age groups in healthy persons in Tehran-Iran. J Mycol Med. 2017;27(4):501-5. https:// doi.org/10.1016/j.mycmed.2017.08.007 (Epub 2017 Sep 28 PMID: 28967539).

70. Shah S, Donze-Reiner T, Shah V. Diversity of navel microbiome in young adults. J Med Microbiol. 2020;69(5):721-7. https://doi.org/10.1099/jmm.0. 001192 (Epub 2020 May 5 PMID: 32369006).

71. Calderone RA, Clancy CJ. Candida and Candidiasis. 2nd ed. Washington, DC: American Society of Microbiology; 2012.

72. Dalton T, Dowd SE, Wolcott RD, Sun Y, Watters C, Griswold JA, Rumbaugh KP. An in vivo polymicrobial biofilm wound infection model to study interspecies interactions. PLoS One. 2011;6:e27317. https://doi.org/10. 1371/journal.pone.0027317.

73. Percival SL, McCarty SM, Lipsky B. Biofilms and wounds: an overview of the evidence. Adv Wound Care (New Rochelle) 4:373-381. 11. Rhoads DD Wolcott RD, Sun Y, Dowd SE. 2012. Comparison of culture and molecular identification of bacteria in chronic wounds. Int J Mol Sci. 2015;13:253550. https://doi.org/10.3390/ijms13032535.

74. Kalan L, Loesche M, Hodkinson BP, Heilmann K, Ruthel G, Gardner SE, Grice EA. Redefining the Chronic-Wound Microbiome: Fungal Communities Are Prevalent, Dynamic, and Associated with Delayed Healing. mBio. 2016;7(5):e01058-16. https://doi.org/10.1128/mBio.01058-16.

75. Perlin DS, Shor E, Zhao Y. Update on antifungal drug resistance. Curr Clin Microbiol Rep. 2015;2:84-95.

76. Serpa R, Franca EJ, Furlaneto-Maia L, Andrade CG, Diniz A, Furlaneto MC. In vitro antifungal activity of the flavonoid baicalein against Candida species. Jour of Med Micro. 2012;61(Pt. 12):1704-8.

77. Uzun O, Kocagöz S, Cetinkaya Y, Arikan S, Unal S. In vitro activity of a new echinocandin, LY303366, compared with those of amphotericin $\mathrm{B}$ and fluconazole against clinical yeast isolates. Antimic Agt Chemo. 1997:41:1156-7.

78. Pakshir K, Zomorodian K, Zakaei A, Motamedi M, Ghiasi MR, Karamitalab M. Molecular identification and in vitro antifungal susceptibility testing of Candida species isolated from patients with onychomycosis. Curr med mycol. 2015;1 (4):26.

79. Neelofar K, Shreaz S, Rimple B, Muralidhar S, Nikhat M, Khan LA. Curcumin as a promising anticandidal of clinical interest. Can J Microbiol. 2011;57(3):204-10. https://doi.org/10.1139/W10-117 (PMID: 21358761).

80. Sohnle PG, Hahn BL, Erdmann MD. Effect of fluconazole on viability of Candida albicans over extended periods of time. Antimic Agt Chemo. 1996;40:2622-5.

81. Kontoyiannis DP, Lewis RE. Toward more effective antifungal therapy: The prospects of combination therapy. Br J Haematol. 2004;126:165-75.

82. Carrillo-Muñoz AJ, Finquelievich J, Tur-Tur C, Eraso E, Jauregizar N, Quindós $\mathrm{G}$, et al. Combination antifungal therapy: A strategy for the management of invasive fungal infections. Rev Esp Quimioter. 2014;27:141-58.

83. Marchetti O, Moreillon P, Glauser MP, Bille J, Sanglard D. Potent synergism of the combination of fluconazole and cyclosporine in Candida albicans. Antimic Agt Chemo. 2000;44:2373-81.

84. Onyewu C, Eads E, Schell WA, Perfect JR, Ullmann Y, Kaufman G, et al. Targeting the calcineurin pathway enhances ergosterol biosynthesis inhibitors against Trichophyton mentagrophytes in vitro and in a human skin infection model. Antimic Agt Chemo. 2007;51:3743-6. 
85. Davis SC, Li J, Gil J, Head C, Valdes J, Glinos GD, Solis M, Higa A, Pastar I. Preclinical evaluation of a novel silver gelling fiber dressing on Pseudomonas aeruginosa in a porcine wound infection model. Wound Rep Reg. 2019;27(4):360-5.

86. Schultz G, Bjarnsholt T, James GA, Leaper DJ, McBain AJ, Malone M, Stoodley P, Swanson T, Tachi M, Wolcott RD, Panel ftGWBE. Consensus guidelines for the identification and treatment of biofilms in chronic nonhealing wounds. Wound Rep and Reg. 2017;25(5):744-57.

87. Ganesh K, Sinha M, Mathew-Steiner SS, Das A, Roy S, Sen CK. Chronic Wound Biofilm Model. Adv Wound Care. 2015;4(7):382-8.

\section{Publisher's Note}

Springer Nature remains neutral with regard to jurisdictional claims in published maps and institutional affiliations.

- fast, convenient online submission

- thorough peer review by experienced researchers in your field

- rapid publication on acceptance

- support for research data, including large and complex data types

- gold Open Access which fosters wider collaboration and increased citations

- maximum visibility for your research: over 100M website views per year

At BMC, research is always in progress.

Learn more biomedcentral.com/submissions 